\title{
A Movement-Associated Fast Rolandic Rhythm
}

\author{
Richard S. McLachlan and Lai Wo S. Leung
}

\begin{abstract}
A stereotyped $32 \mathrm{~Hz}$ rolandic rhythm maximal over the mesial cortex and occurring only with voluntary movement is described in a patient with tonic postural seizures. This abnormal but nonictal rhythm, which is probably generated subcortically, is expressed synchronously at the level of the cortex and peripherally in the EMG.
\end{abstract}

RÉSUMÉ: Rythme rolandique rapide associé au mouvement. Nous décrivons un rythme rolandique stéréotypé de $32 \mathrm{~Hz}$, localisé au cortex mésial et survenant seulement au mouvement volontaire, chez un patient présentant des convulsions toniques posturales. Ce rythme anormal mais non-ictal, qui est probablement généré dans le sous-cortex, est exprimé de façon synchrone au niveau du cortex et en périphérie à l'EMG.

Can.J. Neurol. Sci. 1991; 18:333-336

A number of stereotyped brain wave rhythms have been described in humans which differ in frequency and location as well as reactivity. In particular, the perirolandic region encompassing the pre- and post-central gyri is characterized by a number of medium and high frequency rhythms, the most easily recognized of which is the mu rhythm.' During the course of telemetry recording of the electrocorticogram (ECoG) using subdural electrodes in a patient with intractable epilepsy, an unusual high frequency rolandic rhythm was documented which appeared only in association with movement. This is the only one of more than 100 patients with subdural recordings carried out in the Epilepsy Unit at University Hospital to have such a movement-associated rhythm.

\section{Methods}

A 22-year-old, right-handed mentally normal man had 10-30 tonic seizures per day clustered over 2-3 days about twice a month. He would lose awareness without warning, stiffen and fall with head turned right, the right limbs extended and the left arm flexed. Seizure onset was at age 3 months. Birth was one month premature and complicated by hypoglycemic coma of several hours duration. Two cousins had epilepsy and his mother had two febrile convulsions. Tone and reflexes were slightly increased bilaterally, greater on the left, and fine finger movements were reduced bilaterally. MRI and neuropsychological assessment revealed no focal abnormalities. Since the seizures, which were thought to be mesial frontal in origin, were intractable to medical management he was considered for epilepsy surgery. The ECoG from both frontal and temporal lobes was recorded using subdural stainless steel electrodes embedded at 1.5 or $2 \mathrm{~cm}$ intervals in silastic tubing inserted through burr holes (Figure 1). Recordings were made on a Grass
Model 8 electroencephalograph (high frequency filter $70 \mathrm{~Hz}$, time constant $0.12 \mathrm{sec}$ ) and stored on FM tape (Teac SR 70). The EMG was recorded from the left thenar eminence using silver-silver chloride electrodes (Mactrodes) wired to a Clarke Davis Advantage electromyograph. The taped records were replayed for computer digitization at $200 \mathrm{~Hz}$. Auto- and crosspower spectral analyses were performed as described previously. ${ }^{2}$ The frequency resolution was $0.78 \mathrm{~Hz}$, and the bandwidth was $3.9 \mathrm{~Hz}$. Each spectrum had $>40$ degrees of freedom.

\section{RESULTS}

Interictal recordings of the ECoG using subdural electrodes disclosed right central-sagittal spikes and generalized seizures without focal onset which were expressed maximally in the right hemisphere. It was noted during the course of these recordings that every time the patient moved, a stereotyped welldeveloped $32 \mathrm{~Hz}$ rhythm with a harmonic of $16 \mathrm{~Hz}$ appeared over both rolandic regions, principally expressed over the mesial cortex bilaterally (Figures 2 and 3). The movement-associated rhythm was greatest over the postcentral gyrus not the motor, premotor or supplementary motor areas and was in contrast to the slow intermittent $6-9 \mathrm{~Hz}$ mu and occasional beta rhythm which occurred in the same region when the patient was not moving. The rhythm did not change after all medications had been discontinued. Movements were carried out normally with no associated tremor or myoclonus. The rhythm was elicited from voluntary but not passive movement during wakefulness but also appeared if the patient moved in light sleep. It was better developed with distal finger or toe movements than with proximal limb movements and was most pronounced and persistent with complex movements involving the hands such as opening mail or peeling an orange (Figure 3). Sample move-

From the Department of Clinical Neurological Sciences, University Hospital, London

Received October 23, 1990. Accepted in final form February 26, 1991

Reprint requests to: Dr. Richard S. McLachlan, Department of Clinical Neurological Sciences, University Hospital, 339 Windermere Road, London, Ontario, Canada N6A 5A5 
ments such as slight flexion of the thumb, wiggling of the toes or wiggling the tongue were sufficient to produce the rhythm, whereas thinking about moving a limb and sensory stimulation had no effect. The rhythm was bilaterally expressed and could appear either symmetrically or greater in the right mesial cortex. The side of the movement did not predict the presence of asym- metry. No movement associated rhythms were seen in the scalp EEG, including from the midline electrodes.

To demonstrate the relationship between ECoG and EMG activity, a bipolar surface electrode was used to deliver a single pulse which was below the motor threshold to the left median nerve at the wrist. The patient was instructed to immediately

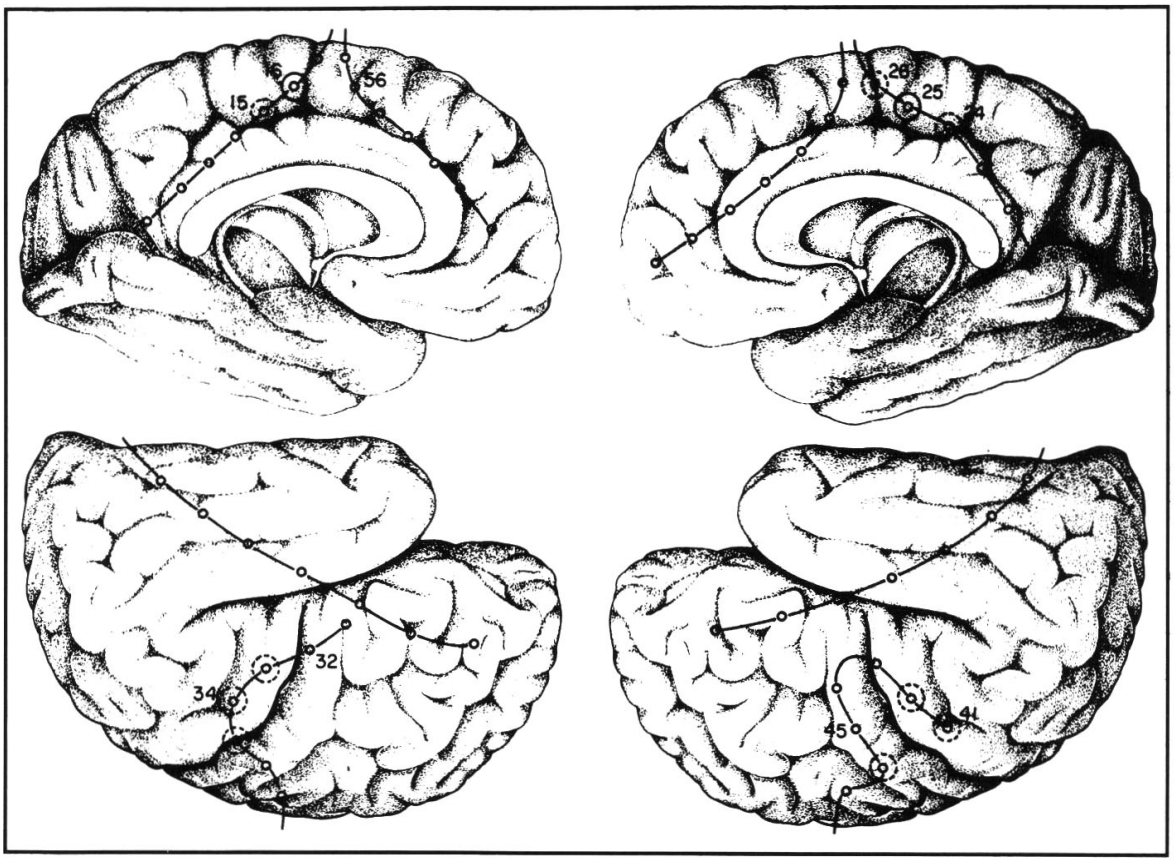

Figure I - Positioning of subdural strip electrodes. Electrodes referred to in Figures 2 and 3 are numbered. Solid circles (electrodes 16 and 25) represent the area of maximum expression of the movement associated rhythm. Dashed circles are other areas where the rhythm is expressed.

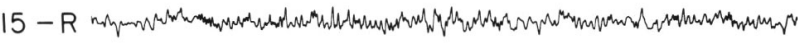

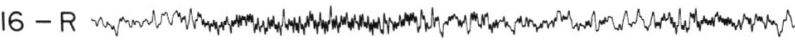

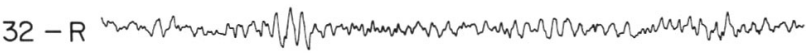

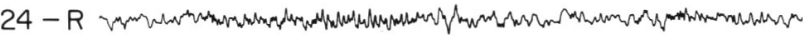

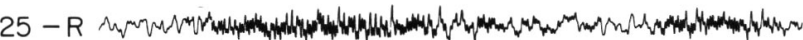

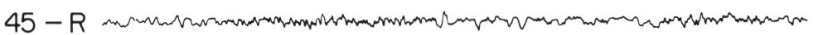

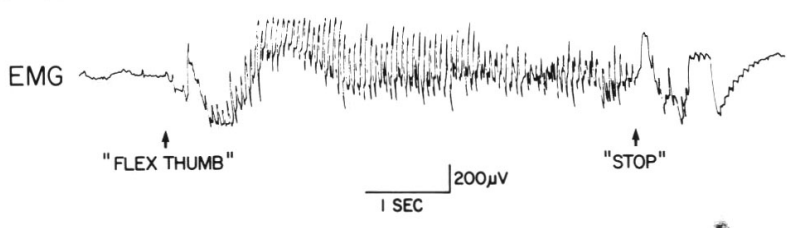

Figure 2 - ECoG during flexion of the left thumb against resistance. Note $32 \mathrm{~Hz}$ rhythm at electrodes 16 and 25 with a subharmonic frequency of $16 \mathrm{~Hz}$ at electrodes 15 and 24. The same activity on relaxation may relate to simultaneous contraction of thumb extensor muscles. EMG is recorded from the left thenar eminence. For electrode positions, see Figure $1 . R=$ linked ear reference.

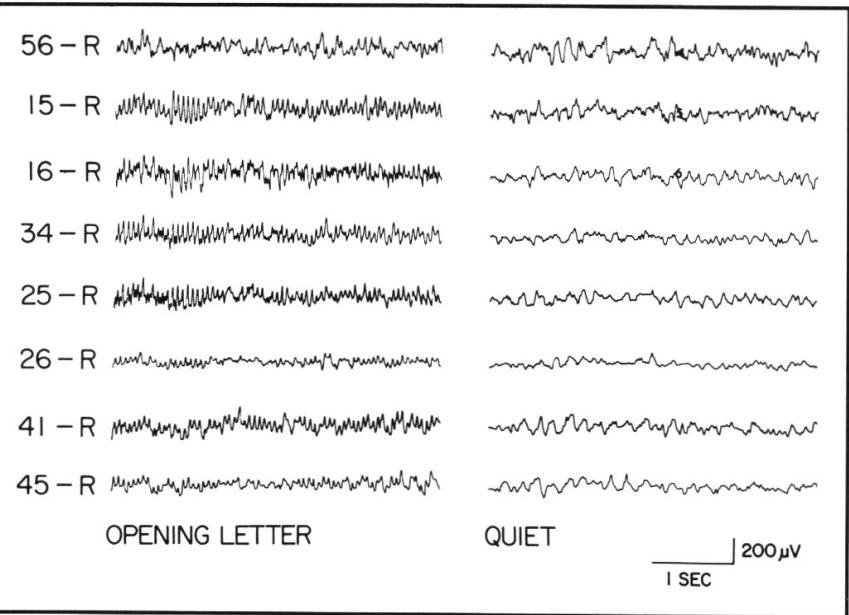

Figure 3 - ECoG while patient was opening letter and immediately after he was told to put letter down and lie still. 
flex his thumb against resistance when he felt the stimulus and to relax the thumb on command. Simultaneous recording of ECoG and EMG activity from the left thenar eminence during thumb flexion revealed that the central rolandic rhythm usually followed the onset of muscle activity and never preceded it (Figure 4). At times, the motor unit activity in the muscle assumed a $16 \mathrm{~Hz}$ rhythm which corresponded to the subharmonic frequency seen in the ECoG. Ten, 20,30 and $50 \mathrm{~Hz}$ stimulation of the median nerve, both below and above the motor threshold (the latter producing sustained muscle contraction), induced rhythmic low voltage evoked potentials over the right rolandic region but did not reproduce the much higher voltage abnormal mesial cortex rhythm described above. The area of maximum evoked potential expression overlapped that of the movement induced rhythm in the post central region.

Using autopower spectrum analysis both 16 and $32 \mathrm{~Hz}$ spectral peaks were detected in the ECoG and EMG (Figure 5). The $32 \mathrm{~Hz}$ peak tended to be larger in the ECoG and the $16 \mathrm{~Hz}$ peak larger in the EMG. Coherence between ECoG recorded from different electrodes was high at $16 \mathrm{~Hz}$ and typically even higher at $32 \mathrm{~Hz}$. The phase shift between ECoGs was typically $0^{\circ}$. Phase shift between ECoG and EMG was about $108^{\circ}$ and $157^{\circ}$ at 16 and $32 \mathrm{~Hz}$ respectively. There was little EMG-ECoG coherence during immobility.

\section{DISCUSSION}

The reactivity of brain rhythms to afferent input, whether it be sensory, motor or behavioural, is almost always one of desynchronization or a decrease in spectral power. An exception to this rule is the augmentation by walking of rhythmic theta and beta activity in the rat hippocampus ${ }^{2}$ and cingulate cortex. ${ }^{3}$ A similar movement-activation of hippocampal rhythms has not been demonstrated in man.4.5 However, an increase in spectral power of non-hippocampal spindle activity has been reported with somatosensory stimulation in a comatose patient. ${ }^{6}$ Five patients with action myoclonus were also reported to have bilateral $20-40 \mathrm{~Hz}$ EEG rhythms maximally expressed over the rolandic area during voluntary movement of the limbs. ${ }^{7}$ These

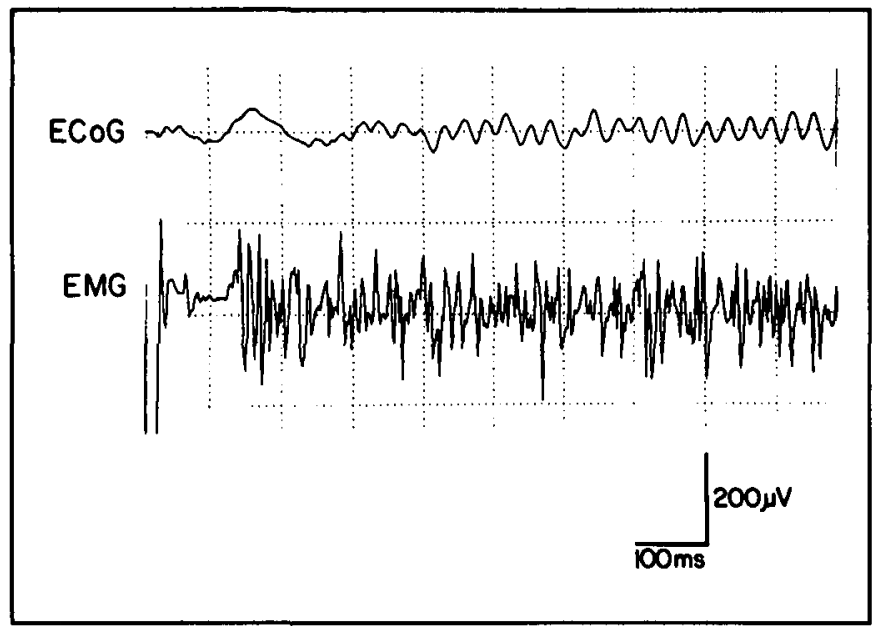

Figure 4 - Oscilloscope display of ECoG from single subdural electrode 16 over left postcentral region and EMG from left thenar eminence during flexion of left thumb. movements were not normal, consisting of a tremor-like "rapid, irregular and asynchronous low amplitude jerking"; the accompanying EEG findings probably reflect an ictal pathophysiology similar to the repetitive central spikes associated with myoclonic jerks of myoclonic epilepsy. ${ }^{8}$

Veilleux et al, in a retrospective study, ${ }^{9}$ reported that fast central midline rhythms occurred in association with movement in 12 of 36 patients, 9 of whom had seizures, 2 shaky-leg syn-

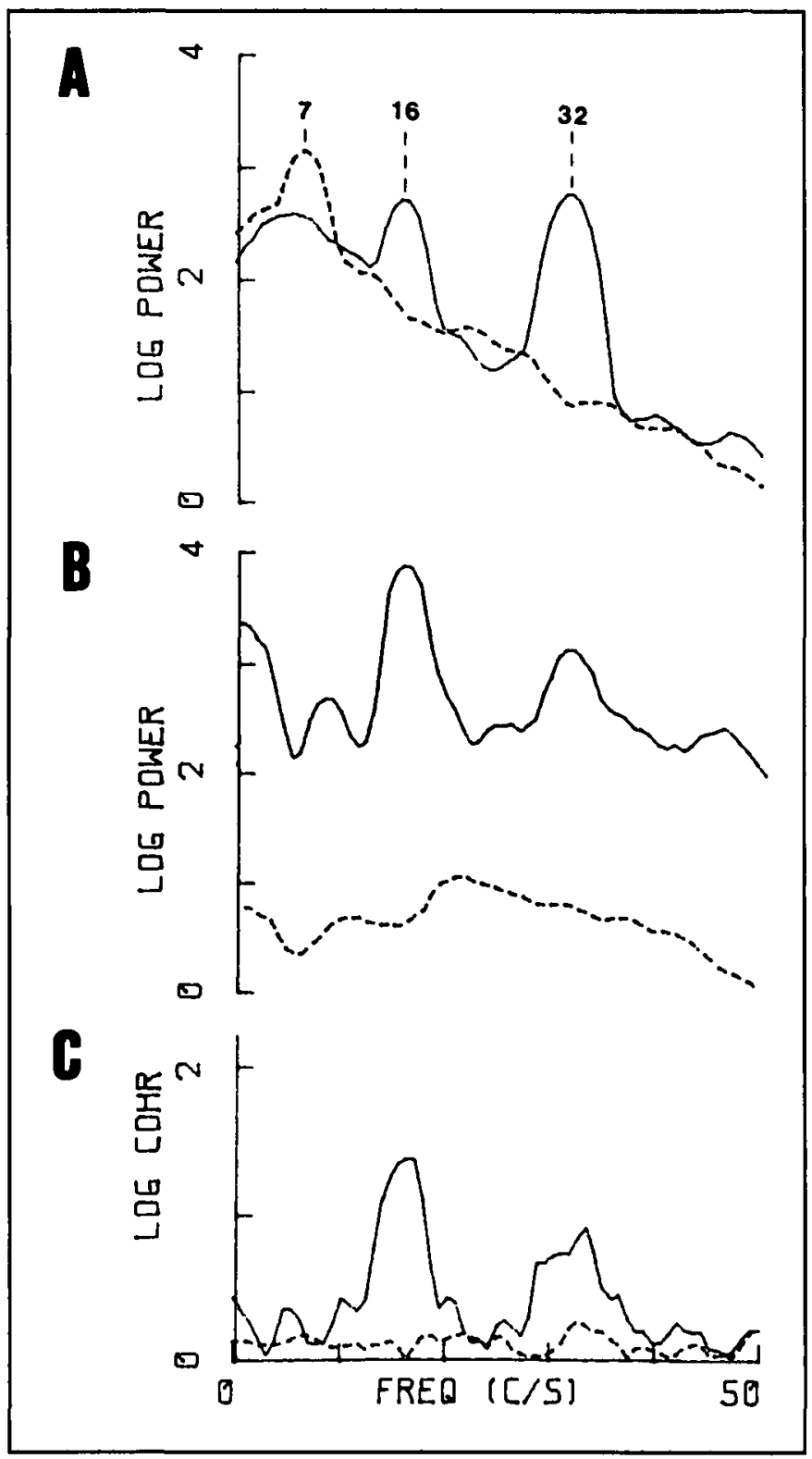

Figure 5 - A Autopower spectra of single ECoG channel during thumb movement and during relaxed immobility (dashed line). Note slow $7 \mathrm{~Hz} \mathrm{mu}$ rhythm which attenuates with movement (df $>60$ for both spectra). B Autopower spectra of the thenar EMG during thumb movement reveals modulation of activity which peaks at 16 and $32 \mathrm{~Hz}$. During relaxed immobility (dashed line) activity is almost zero. C Z-transformed linear coherence between EMG and ECoG is high at 16 and $32 \mathrm{~Hz}$ during movement but not during relaxed immobility. 
drome and 1 dementia. The fast, movement-associated rhythm has, therefore, been found only in patients with neurological disease and usually when seizures are a prominent part of the condition. ${ }^{9}$ The sub-harmonic rhythm of our patient corresponds to the mean frequency of $16 \mathrm{~Hz}$ recorded in the study of Veilleux et al. The bilateral distribution over both rolandic regions and the maximum expression at the midline also correspond to the findings in that study.

While the movement associated rhythm was greatest at electrodes over the mesial post-central gyrus, direct sensory input from the periphery did not elicit the rhythm and passive movement had no effect suggesting that afferent activity from muscle contraction was not driving the abnormal brain activity. This is supported by the fact that the EMG activity never preceded the rhythmic waves in the cortex. In addition, the rhythm exhibited none of the characteristics of a seizure which could induce a rhythmic EMG response. We postulate that a central subcortical, possibly thalamic, "pacemaker" drives both the cortical fast rhythm and the rhythmic EMG activity. The differences in time delays from such a pacemaker to the cortex and to the periphery are perhaps responsible for the phase shifts in the coherence analysis. The $9 \mathrm{~Hz}$ rhythm at the sensory motor cortex in rat 10 and the 4-6 Hz thalamic rhythm of Parkinsonian patients ${ }^{11}$ are each associated with rhythmic peripheral EMG activity. The ventrobasal thalamus is probably the pacemaker of these rhythms. ${ }^{10,11}$ Another $35-45 \mathrm{~Hz}$ fast rhythm found in motor and parietal cortex of cats is driven by the posterior thalamus during alert immobility. ${ }^{12}$ Fast rhythms may normally be present in the cortex 2,3 and serve to establish transient relations between spatially distributed features of a sensory stimulus ${ }^{13}$ or motor command. The rhythm in our patient may indicate an abnormal mode of this sensory motor processing.

\section{ACKNOWLEDGEMENT}

We thank Dr. W. Brown for use of his EMG facilities and Miss Heather Murray for typing the manuscript.

\section{REFERENCES}

1. Kozelka JW, Pedley TA. Beta and Mu rhythms. J Clin Neurophysiol 1990; 7: 191-207.

2. Leung LWS, Lopes Da Silva FH, Wadman WJ. Spectral characteristics of the hippocampal EEG in the freely moving rat. Electroenceph Clin Neurophysiol 1982; 54: 203-219.

3. Leung LWS, Borst JGG. Electrical activity in the cingulate cortex of the rat. I. Generating mechanisms and relations to behaviour. Brain Res 1987; 407: 68-80.

4. Halgren E, Babb TL, Crandall PH. Human hippocampal formation EEG desynchronizes during attentiveness and movement. Electroenceph Clin Neurophysiol 1978; 44: 778-781.

5. Huh K, Meador KJ, Lee GP, et al. Human hippocampal EEG: effects of behavioural activation. Neurology 1990; 40: 1177 1181.

6. Pfurtscheller G, Schwarz G, Pfurtscheller F, et al. Quantification of spindles in comatose patients. Electroenceph Clin Neurophysiol 1983; 56: 114-116.

7. Kelly JJ, Sharbrough FW, Westmoreland BF. Movement-activated central fast rhythms: an EEG finding in action myoclonus. Neurology 1978; 23: 1037-1040.

8. Engel J, Rapin I, Giblin DR. Electrophysiological studies in two patients with cherry red spot - myoclonus syndrome. Epilepsia 1977; 18: 73-87.

9. Veilleux M, Westmoreland BF, Sharbrough FW. Fast central midline rhythm. J Clin Neurophysiol 1987; 4: 302-303.

10. Semba K, Szechtman H, Komisaruk BR. Synchrony among rhythmical facial tremor, neocortical "Alpha" waves, and thalamic non-sensory neuronal bursts in intact awake rats. Brain Res 1980; 195: 281-298.

11. Bertrand $\mathrm{G}$, Jasper $\mathrm{H}$, Wong A, et al. Microelectrode recording during stereotaxic surgery. Clin Neurosurg 1969; 16: 328-355.

12. Bouyer JJ, Montaron MF, Rougeul-Buser A, et al. A thalamo-cortical rhythmic system accompanying high vigilance levels in the cat. In: Pfurtscheller G, et al. (eds.). Rhythmic EEG activities and cortical functioning. Amsterdam: Elsevier, 1980, 63-77.

13. Gray CM, Konig P, Engel AK and Singer W. Oscillatory responses in cat visual cortex exhibit inter-columnar synchronization which reflects global stimulus properties. Nature 1989; 338: 334-337. 